\title{
Experimental Investigation of Solar Powered Reverse Osmosis Desalination
}

\author{
Petros Gebray*, Ashenafi Kebedom and Fana Filli \\ Department of Mechanical Engineering, Ethiopian Institute of Technology (EiT-M), Mekelle \\ University, Mekelle, Ethiopia (*ghpeterkid@yahoo.com)
}

\begin{abstract}
Pollution and over exploitation of groundwater aquifer and surface water have led to a decrease of quality and availability of natural water resource in many regions. This situation has led to elevated total dissolved solids (TDS) beyond standards and facilitates toxic metals accumulation and other problems like staining and/or precipitation. One of the treatment options for an elevated total dissolved solution is desalination using a solar driven reverse osmosis system. The northern part of Ethiopia has short rainy season and long dry weather with clear sky radiation. Solar radiation ranges from $5.46 \mathrm{kWh} / \mathrm{m}^{2} /$ day in August to $6.82 \mathrm{kWh} / \mathrm{m}^{2} /$ day in April, with an average of $6.09 \mathrm{kWh} / \mathrm{m}^{2} /$ day.

This paper deals with application of reverse osmosis, driven by desalination system using solar energy, to supply safe drinking water for the rural areas of northern Ethiopia. Reverse osmosis due to its low energy consumption is one of the best desalination alternatives. Solar powered reverse osmosis system was developed and installed at Mekelle University. The main components are photovoltaic panels, two DC powered pumps, carbon filters, and flow meters. The system made to operate in a variable power, flow, and pressure considering the naturally varying irradiance throughout the day. The entire process of irradiation potential measurements, the amount of energy generated using solar panel, and the amount of TDS is discussed. The feed water with nearly constant TDS around $2800 \mathrm{ppm}$ from the study area has reduced to fairly constant TDS of about $100 \mathrm{ppm}$ after desalination. The average desalination capacity of the system is 50 litres per hour.
\end{abstract}

Keywords: Carbon filter; Desalination; Flow meter; Reverse osmosis; Photovoltaic cells, Ethiopia.

\section{INTRODUCTION}

Safe drinking water is a human birthright - as much a birthright as clean air. As a matter of fact, in most of the African, Asian countries and even in the relatively developed countries such as India, safe drinking water is not easily available (TWAS, 2002). Water scarcity is one of the world's leading problems affecting more than 1.2 billion people globally. This number is growing fast and by 2025, about 1.8 billion people will be living in regions or countries with absolute water scarcity (UN-Water, 2014). Exploitation of groundwater aquifers and surface water has led to a decrease of quantity and/or quality of available natural water resources in many regions (Fritzmann et al., 2007). About 2.5 billion do not have access to adequate sanitation services (Gebrekidan and Samuel, 2011). 
In rural Ethiopia, the water problem is twofold, in addition to call for filtration device; women and children travel on foot for six hours to collect water (Ambika et al., 2013). Most people collect water from shallow, unprotected ponds and wells sharing with animals. The sources are subjected to contamination as rain water washes waste from surrounding areas into them. Besides, the jugs that the women use to carry water back to the village, weigh up to $18.2 \mathrm{~kg}$. Often, young children are left at home while their mother and older siblings collect water and their fathers work (Water.org, 2013). In developing countries like Ethiopia, composed of numerous villages and farmers, it is very difficult to extend an electric grid to every rural area to fulfill the basic needs of the residents. This is because, most of the residents are located in valleys and hills, and they also live dispersedly. Excessive exploitation of natural fresh water resources combined with higher water demand has led to an increased demand for alternative fresh water resources (Fritzmann et al., 2007). Hence, lack of safe drinking water is still an issue to be solved in many of these rural areas, which calls a systematic approach.

The northern part of Ethiopia has short rainy season and dry weather with clear sky radiation. Solar radiation ranges from the minimum of $5.46 \mathrm{kWh} / \mathrm{m}^{2} /$ day in August to $6.82 \mathrm{kWh} / \mathrm{m}^{2} /$ day in April, with an average of $6.09 \mathrm{kWh} / \mathrm{m}^{2} /$ day. These values showed that there a good sun exposure favoring for implementing solar photovoltaic (PV) reverse osmosis (RO) desalination technology. The fast development of solar energy, especially photovoltaic, is making the proposed technology very attractive for such applications. Power from PV electricity is not yet cost effective when compared to the supply from the typical national electric grid. However, for smaller loads, PV system, which is Stand-alone system, is cost effective comparing with the cost of extending power from the electric grid. Thus, the use of solar energy technology, a standalone power system, to desalinate water from wells is a viable solution to provide fresh water for the residents living in rural and remote areas.

\subsection{The Process of Solar based Desalination System}

The process of solar desalination and its component is shown in figure 1. In many areas, those suffer from severe water scarcities; the dependence on desalination is increasing, as it is a highly reliable, non-conventional source of fresh water (Global water intelligence, 2004). Desalination is a separation process used to reduce the dissolved salt content of saline water to a usable level. Desalination process (Fig 1) involves three liquid streams: the saline feed water, low-salinity product water, and very saline concentrate - brine or reject water (Abdallah et al., 2005). Sea or 
brackish water desalination are the most favorable non-conventional water resources, based on criteria of reliability, availability, economic and technical feasibility and environmental sustainability (Mohsen, 2002).

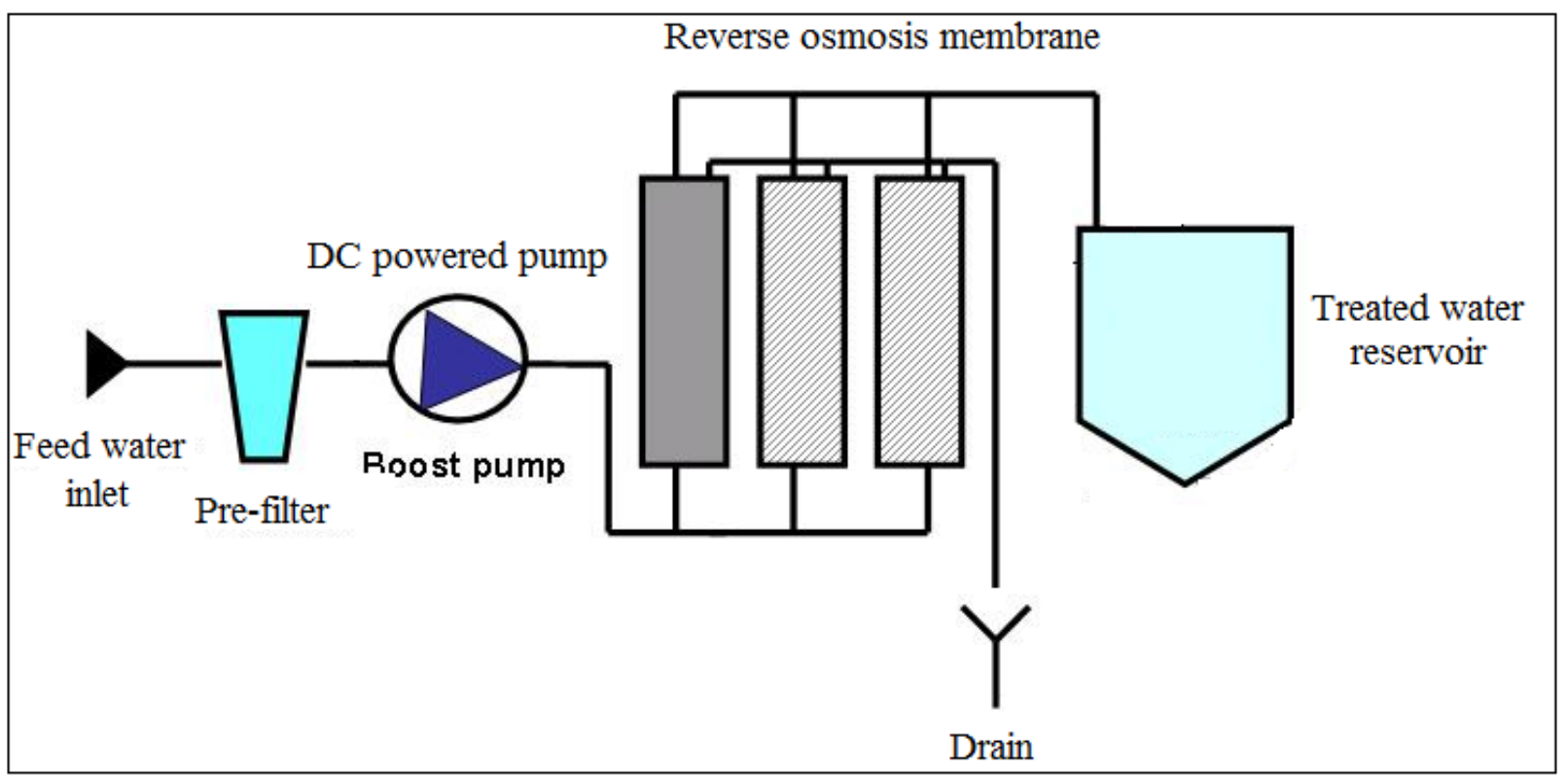

Figure 1. Schematics diagram, process flow of Reverse Osmosis.

Desalination processes consume large amounts of energy thus become an impetus towards developing renewable energy powered processes at the medium to large scale (Burgess and Lovergrove, 2005). It is estimated that the production of $100 \mathrm{~m}^{3} / \mathrm{d}$ of fresh water requires 10,000 tons of oil per year (Kalogirou, 1996). This is significant as it involves a high recurrent energy expense, in which a few water-short areas of the world can afford. Solar PV desalination provides an alternative source for offering clean water. Desalination technologies can be classified, by their separation mechanism, into thermal and membrane based desalination. Thermal desalination separates salt from water by evaporation and condensation; whereas in membrane desalination, water diffuses through a membrane, while salts are almost completely retained (Fritzmann et al., 2007). Among desalination technologies, reverse osmosis is rapidly overtaking thermal desalination in terms of market shares (Andrea and Messalem, 2009). It is a pressure-driven process that relies on the properties of semi-permeable membranes to separate water from a saline feed. The end result comprises the flows of freshwater permeate and concentrated brine. System flow rate is proportional to the difference between the applied pressure and the osmotic pressure - differential between brine and dilute compartments. Reverse 
osmosis coupling with solar PV systems holds great promise for increasing water supplies in water scarce regions (Al-Karaghouli, 2010).

\subsection{Solar Photovoltaic (PV) and Reverse Osmosis (RO) Systems Application}

Reverse osmosis is a form of filtration in which the filter is a semi-permeable membrane that allows water, but not salt, to pass through. Photovoltaic-powered reverse osmosis is considered one of the most promising forms of renewable-energy-powered desalination, especially for remote areas. Therefore, small-scale PV-OR has got much attention in recent years. RO units are available in a wide range of capacities due to their modular design. Large plants are made of hundreds of units that are accommodated in racks. A typical maximum plant capacity is 128,000 $\mathrm{m}^{3} /$ day, and very small units (down to $0.1 \mathrm{~m}^{3} /$ day) are also used for marine purposes, houses or hotels. PV power is used for small-size RO units due to initial cost benefits (ARMINES, 1996). Hence, this study deals with experimentation so as to understand applicability of solar photovoltaic driven reverse osmosis desalination to provide a safe drinking water from their nearby shallow wells and ponds for rural areas of Northern Ethiopia. The RO system unit used for the experiment uses carbon filters which are to filter declorinate and desalinate a feed water which could be brackish, well or potable city water.

\section{MATERIALS AND METHODS}

\subsection{Experimental Site}

Ethiopia, located at the horn of Africa, lying between $3^{\circ}-15^{\circ}$ latitude and $33^{\circ}-48^{\circ}$ longitude, enjoys sunshine almost through the year. The experimental field is located at an altitude of 2150 meters above sea level, at the Ethiopian Institute of Technology-Mekelle- Department of Mechanical Engineering, Solar Demonstration Center of Mekelle University, on the out skirts of the city of Mekelle, the regional capital of Tigray.

\subsection{Design Data}

At the beginning of the experiment, the reverse osmosis had a capacity of 250 gallons per day (GPD), and reached up to 7,000 GDP. According to the specification of the equipment, the minimum feed pressure for the R.O system is 30 PSI. A reverse osmosis unit consists of the following major subsystems is used for the experimental study: solar photovoltaic panels, small diaphragm pump, high pressure DC pump, membrane module, flow meters, valves and reservoirs. A schematic diagram of the photovoltaic powered reverse osmosis system used in this 
experimental study is presented in figure 2 and the experimental setup is given by figure 3 . The experimental set up consists of PV arrays, batteries, a controller and different loads. The actual performance of the set up depends on various factors especially the meteorological conditions of the locality such as solar radiation. To use the PV systems efficiently and economically, the PV system is designed under the local condition of the system load, irradiation of the application area, temperature and their components' characteristics. The system is mechanically powered by the photovoltaic power system and a DC motor, coupled to a pump, which is capable of providing sufficient torque to run the RO system.

A fixed axis PV system with two PV arrays, connected in series and tilted to $13.6^{\circ}$ south taking into account the latitude of the locality, are used to drive the larger pump. A small PV module with similar orientation is also used to drive the smaller diaphragm pump. The rated voltage, current, and power of the PV arrays for the larger pump are $26.2 \mathrm{~V}, 7.63 \mathrm{~A}, 200 \mathrm{~W}$; and for the smaller PV module 15.7V, 6.10A, 95W respectively. Two DC powered pumps (24V DC, 3.5A diaphragm pump and $0.25 \mathrm{~W}, 24 \mathrm{~V}$ DC motor pumps), carbon filters, and the flow meters are integrated to make the system fully functional. The RO system used carbon filters to desalinate and dechlorinate the feed water.

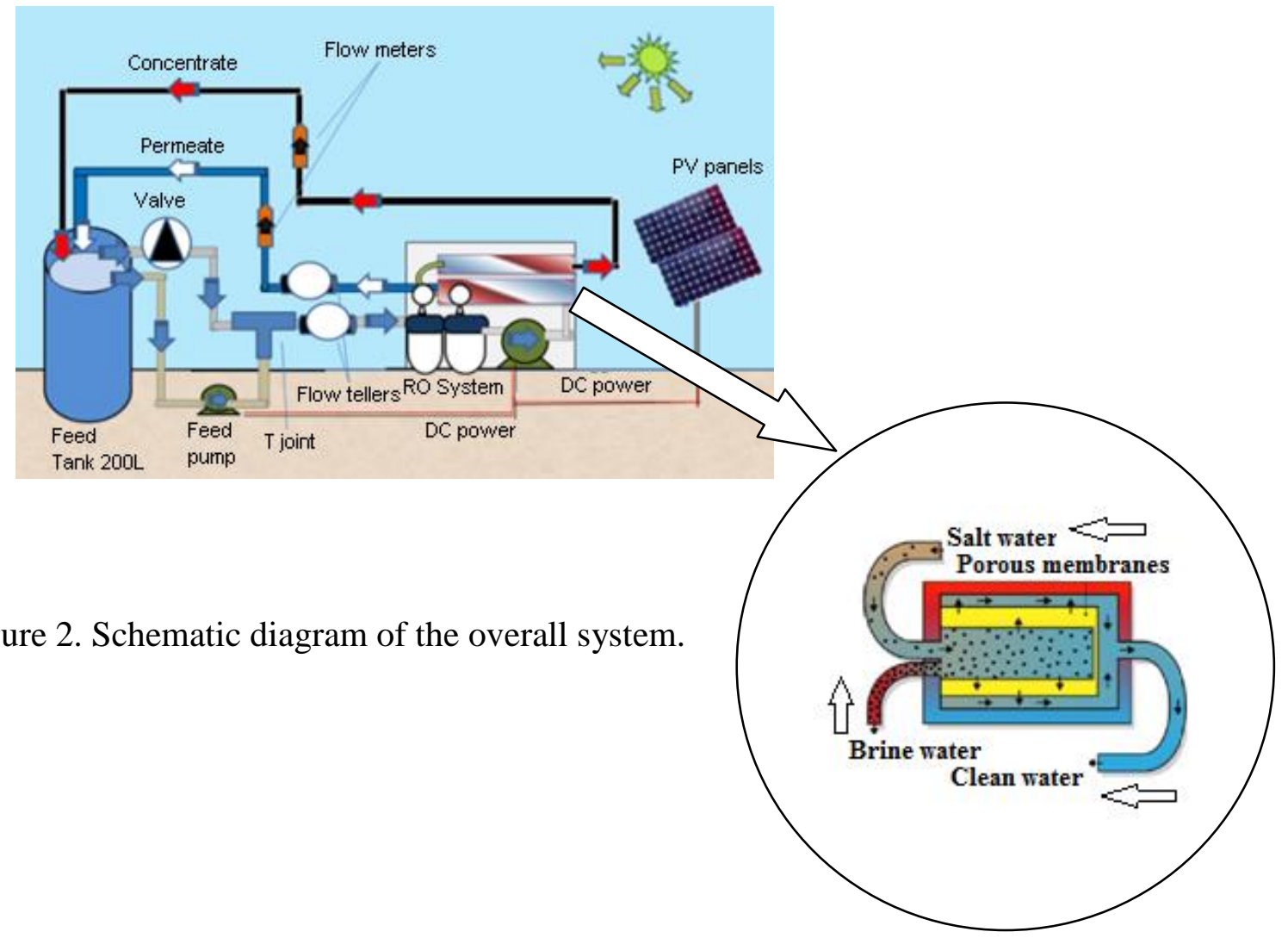

Figure 2. Schematic diagram of the overall system. 


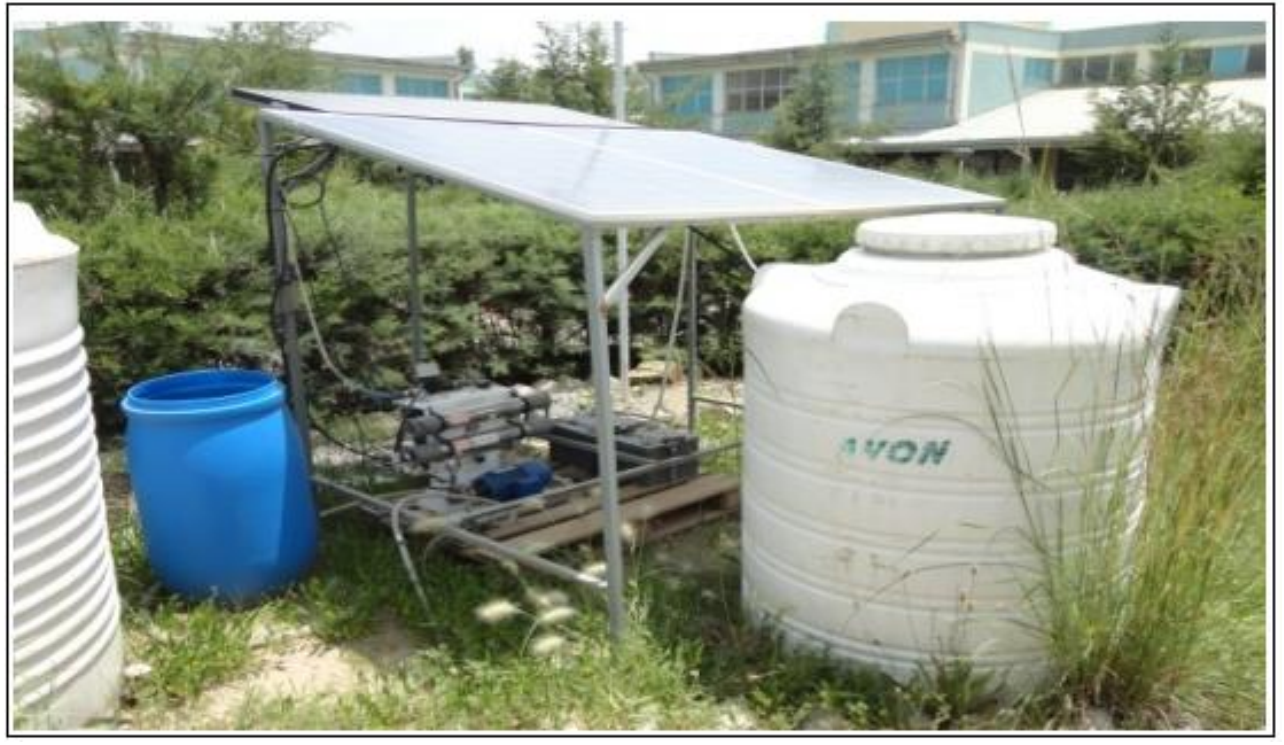

Figure 3. Experimental set up.

Solar energy will be converted into electricity in the solar photovoltaic panels; and then, this will be used to drive the positive displacement DC pumps. The small diaphragm pump is used to pump brackish water from ground water well to the RO pretreatment tank and the other high pressure DC pump is used to pump the feed brackish water to the semi-permeable membranes at the required system feed pressure.. Flow meters are used at different pipe lines on the system which enable to measure flow rates of the brackish and distilled water. Flexible and rigid pipe lines are used to direct the concentrated and distilled water into the respective reservoirs. Flow of the fluid at different positions of the system is regulated using valves.

\section{RESULTS AND DISCUSSION}

Experiments were conducted during the months of December and January, during sunny days. In order to understand parametric relations, experimental results are plotted (refer below graphs) below.

Figures 4 and 5 showed both system pressure and voltage with almost the same trend throughout the experiment daytime. The sharply increase up to $10 \mathrm{AM}$ and keeps constant until $15 \mathrm{PM}$ in the afternoon. And then, it sharply decreased to about the initial value. This might attribute to the variation of the irradiance during the experiment. From these graphs, it can be concluded that the 
system pressure is highly dependent on the system voltage, which in turn is dependent on the irradiance level of the place.

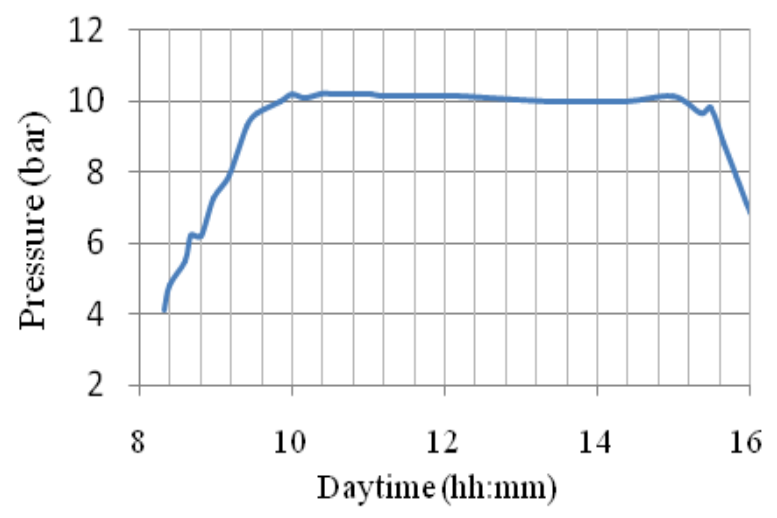

Figure 4. System pressure versus time of the day.

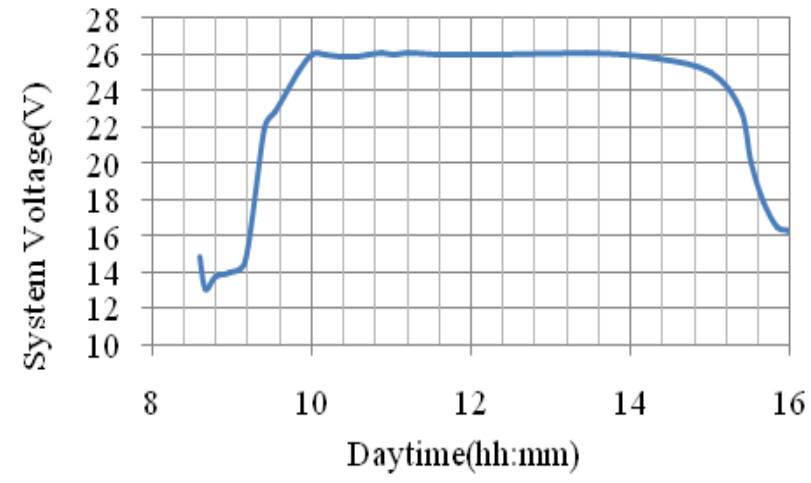

Figure 5. System voltage versus time of the day.

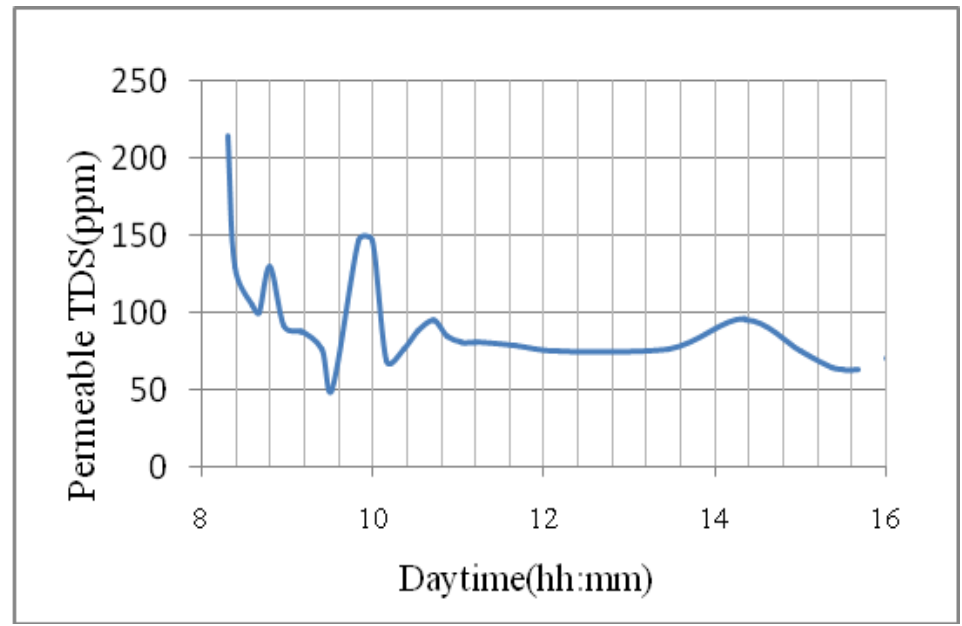

Figure 6. Permeable TDS versus time of the day. 
Figures 6 and 7 showed interesting phenomenon of the permeable and concentrated TDS values in ppm against time. At the beginning of the experiment, the permeable TDS was much higher but after sometime it went down. Conversely, the concentrated TDS was lower initially but it kept increasing until mid-day; and then it starts to fall. Thus, it can be concluded that the desalination process is directly related to the irradiance.

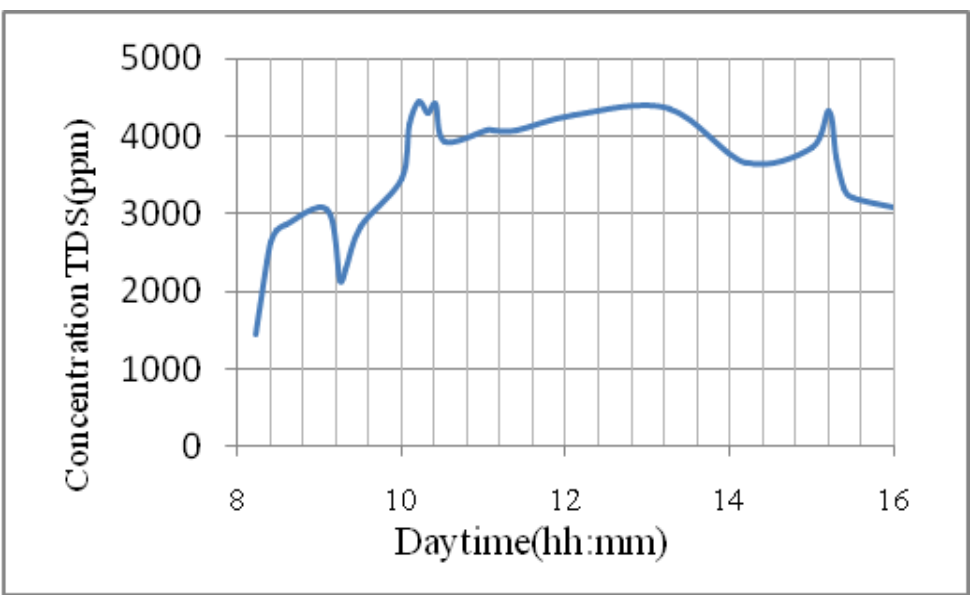

Figure 7. Concentration TDS versus time of the day.

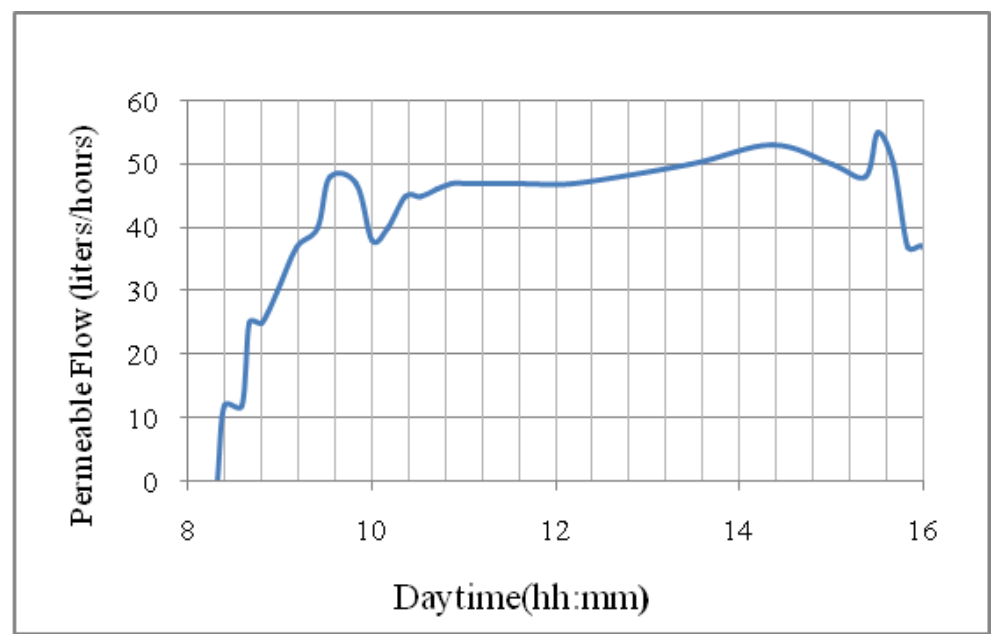

Figure 8. Permeability flow versus time of the day.

Figure 8 showed an increase in permeable flow with the time. There is almost a direct relationship between the two. The may attribute to an increase in irradiance with time, which results in increase in system voltage. This also had same effect for the permeable flow. 


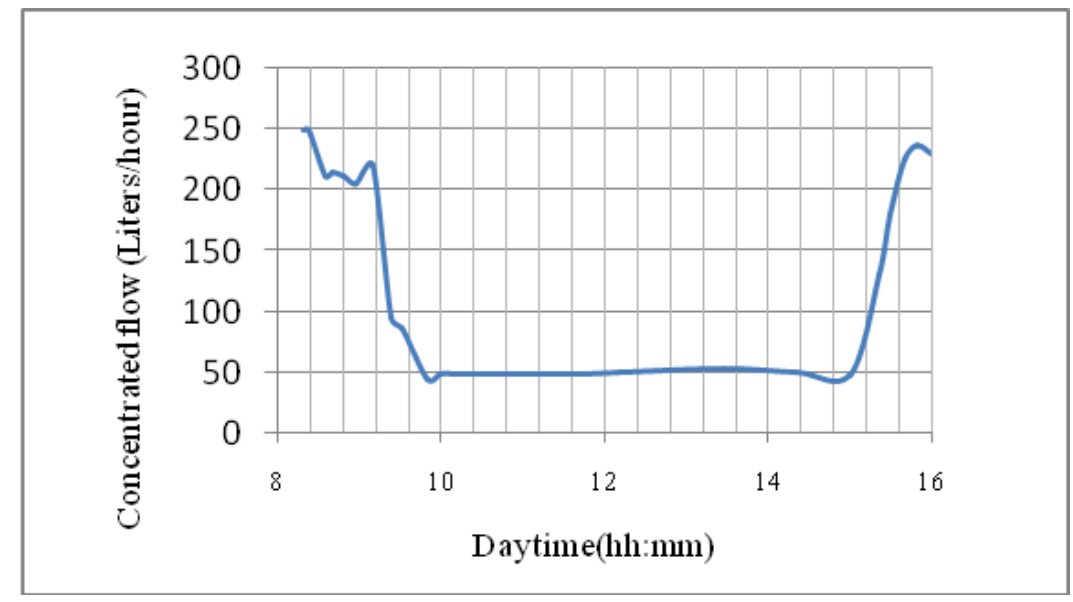

Figure 9. Concentration flow versus time of the day.

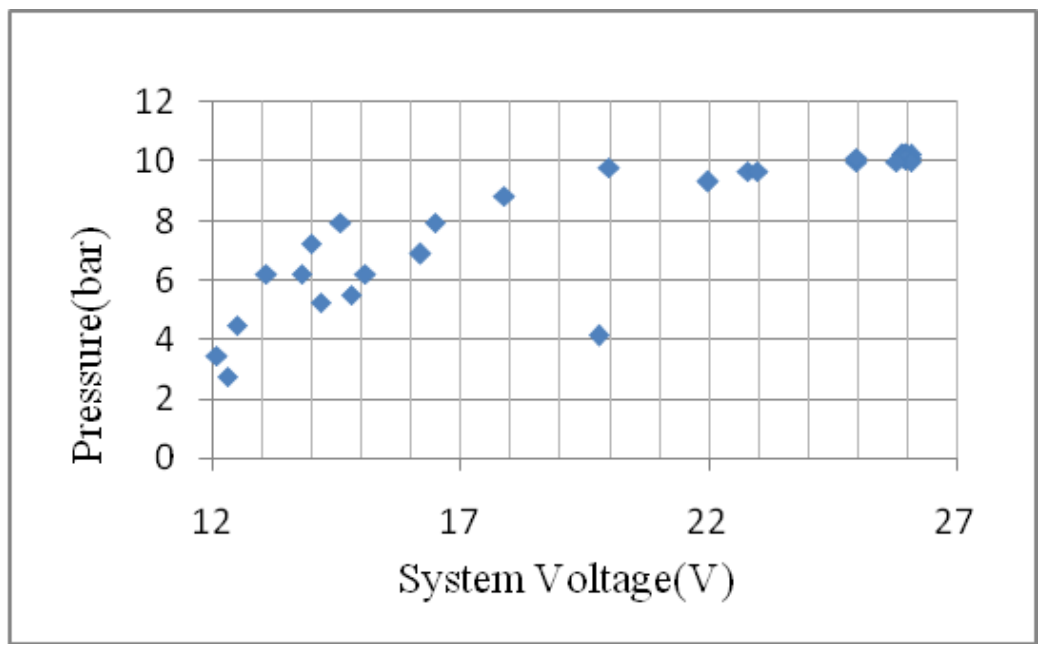

Figure 10. Pressure versus system voltage.

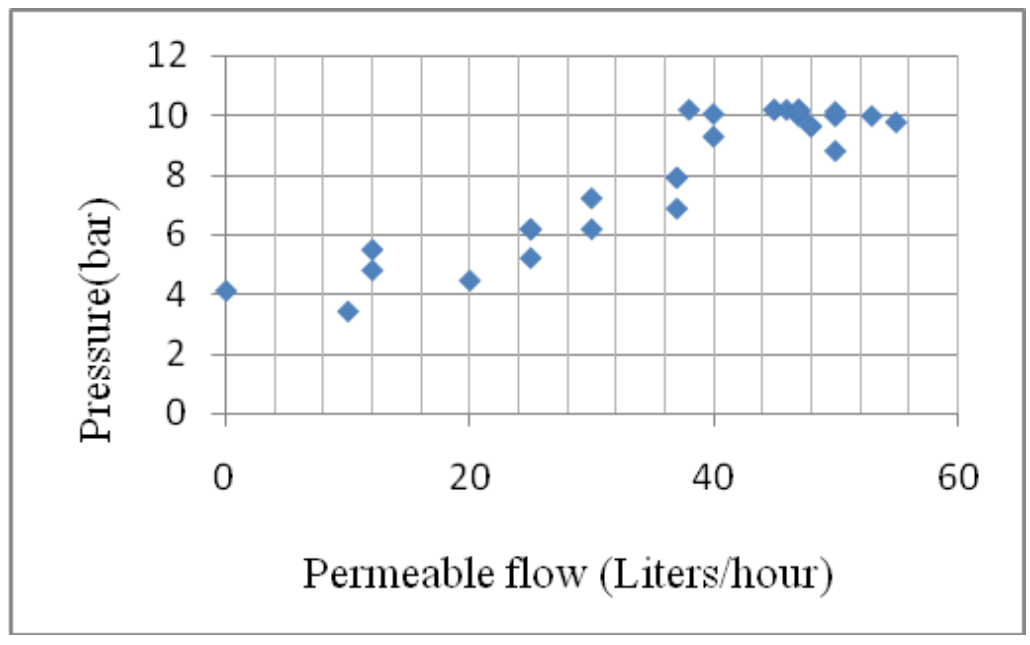

Figure 11. Pressure versus permeability flow. 
Figure 10 showed an increased in system voltage with an increased in pressure, which resulted to the increased purification process. Similarly, figure 11 shows an increased in permeable flow. This may be attributed to an increase in flow pressure facilitated the desalination process.

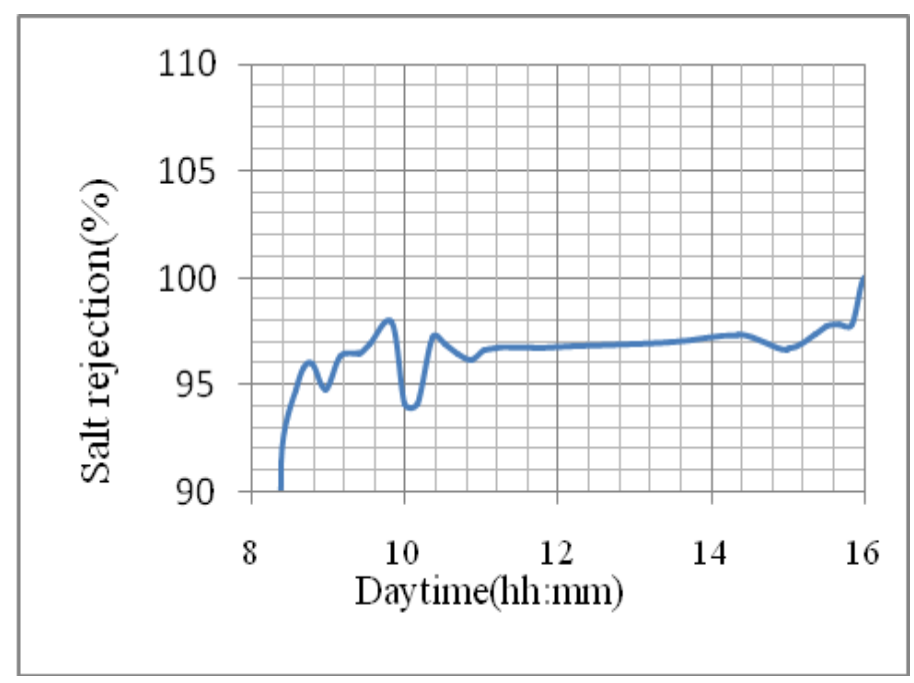

Figure 12. Salt rejection versus time of the day.

Figure 12 showed the direct relationship of the desalination process (salt rejection) with the time during the experiment. The salt rejection process (desalination) increased with time. This is attributed to the increase in irradiance of the locality during the day of the experiment. This is on the outcome of the experiment, in which more salt and other unwanted particles were removed enabling to get a healthy drinking water.

\section{CONCLUSION}

Most of the northern Ethiopia rural areas are located in valley and hills, as well in remote, which made difficult to extend grid electricity. Thus, there is a difficulty to get a safe drinking water for the residents of these rural areas. Fortunately, many of these places have shallows wells and ponds along with a good sun exposure favoring implementing solar PV - RO desalination process.

The experiment showed that the TDS decreased from an average of $2800 \mathrm{ppm}$ to $100 \mathrm{ppm}$ and the concentrated TDS in ppm goes up from 1500 in the morning to more than $4000 \mathrm{ppm}$ at around noon. This resulted with significant decrement of the TDS in the finally treated water. Similarly, 
the percentage of salt rejection throughout the day of the experiment was also considerable. Starting from $90 \%$ early in the morning reached to about $100 \%$ of salt rejection.

Thus, the experimental set up showed that it is possible to use a solar PV driven RO desalination system in areas where the challenges happened. Such system will lessen the difficulty of getting access for appropriate and applicable power so as to source a safe drinking water.

\section{ACKNOWLEDGEMENTS}

The authors are grateful to Mr. Andreas Gonzalez who supported and provided experimental equipment to undertake this study. They also extend gratitude to Farm Technology Research project (MU-IUC) of Mekelle University for supplementing additional equipment and other accessories, which were very helpful to carry out the experiments.

\section{REFERENCE}

Abdallah, S., Abu-Hilal, M \& Mohsen, M.S. 2005. Performane of a photovoltaic powered reverse osmosis system under local climatic conditions. Desalination, 183:95-104.

Al-Karaghouli Ali, Renne, D \& Kazmerski, L.L 2010. Technical and economical assessment of phovoltaic-driven desalination systems. Renewable Energy, 35: 323-328.

Ambika Acharya, Stefano Cestellos Blanco, Preet Hayer \& Hannah Potter. 2013. The H2Olways Filtran: Project Report EE15N, Stanford University

Andrea, G \& Messalem R. 2009. Solar-drien desalination with reverse osmoss: the state of the art. Desalination Publications, pp.285-296

ARMINES. 1996. Technical and economic analysis of the potential for water desalination in the Mediterranean region. RENA-CT94-0063, France

Burgess, G \& Lovergrove, K. 2005, Solar thermal powered desalination: membrane versus distillation technologies, Centre for Sustainable Energy Systems, Australian National Univesity, Canberra Act 0200, Australia,

Fritzmann, C., Lowenberg, J., Wintgens, T \& Melin, T. 2007. State-of-the-art of reverse osmosis desalination. Desalination, 216:1-76.

Gebrekidan, M \& Samuel, Z. 2011. Concentration of Heavy Metals in Driniking Water from Urban Areas of the Tigray Region, Northern Ethiopia. Momona Ethiopian Journal Science, 3(1):105-121 
Global Water Intelligence. 2004. Desalination markets 2005-2015: A global assessment and forecast, Oxford, UK

Kalogirou. 1996. Encyclopedia of Desalination and Water Resources, www.desaware.net

Mohsen, M.S. 2002. Economics of a solar-powered water desalination system, World Renewable Energy Congress, June 29-July 5, Cologne, Germany.

Third World Academy of Sciences (TWAS). 2002. Safe Drinking Water The need, the problem, solutions and an action plan. Report of the Third World Academy of Sciences. Third World Academy of Sciences, Trieste Italy.

United Nations - Water, 2014, Water Scarcity Factsheet. Accessed July 01, 2015.

Water.org project. 2013. water.orgcountry/ethiopia, accessed July 01, 2013. 